\title{
Ulna and tibia length measurements as alternatives for estimating height in hospitalized children
}

\author{
N.E. Lara-Pompa ${ }^{1}$, J. Williams ${ }^{1}$, S. Macdonald ${ }^{2}$, K. Fawbert ${ }^{2}$, J. Valente ${ }^{2}$, K. Kennedy ${ }^{1}$, \\ V. Shaw ${ }^{2}$, J.C. Wells ${ }^{1}$, S. Hill ${ }^{2}$ and M. Fewtrell ${ }^{1}$ \\ ${ }^{1}$ Childhood Nutrition Research Centre, UCL Institute of Child Health, London WC1N 1EH, UK and ${ }^{2}$ Great Ormond \\ Street Hospital for Children NHS Foundation Trust, London WC1N 3JH, UK
}

Height is an important component in the nutritional assessment and management of hospitalized children, however several conditions and situations in clinical practice can interfere with the measurement of standing height ${ }^{(1,2)}$. Ulna and tibia length measurements have been proposed as alternatives to estimate height ${ }^{(3)}$, but their use if still to be fully validated in paediatric patients with a range of conditions. Thus, the study aimed to generate prediction equations using tibia and ulna length measurements from healthy UK children, and test the accuracy of the estimates in a paediatric patients admitted to a tertiary referral hospital.

Standing height, ulna $(n=700,51.7 \%$ male, $10.5 \pm 1.9 \mathrm{yr})$ and tibia length $(n=133,51.9 \%$ male, $13.9 \pm 2 \mathrm{yr})$ measurements were obtained from healthy UK children. Measurements were also obtained in children with a range of medical conditions $(n=70,49 \%$ male, $12 \cdot 5 \pm 3 \mathrm{yr}$ ) within $48 \mathrm{hrs}$ of admission. Tibia and ulna measurements were taken using a non-stretchable tape and standing height using a fixed or portable stadiometer. Prediction equations were calculated and accuracy of the estimates tested using Bland-Altman analysis and Cohen's kappa against standing height and height standard deviation scores (SDS) calculated using 1990 British reference data ${ }^{(4)}$ with abnormal cut-offs of $<-2$ or $>2$ SDS.

Ulna and tibia length measurements could explain a high percentage of variability on height in our reference sample $\left(R^{2}=87\right.$ and 86.6 respectively). Prediction equations adjusting for age and weight resulted in a non-significant mean bias (MB) of $-0.01 \mathrm{~cm}$ and $-0.04 \mathrm{~cm}$ respectively, but with wide limits of agreement (LOA) of $\pm 8.5 \mathrm{~cm}$ and $\pm 8.7 \mathrm{~cm}$ in healthy children. Ulna and tibia estimates of height showed a good agreement $(94 \%$ both, kappa $=0.43)$ to SDS classifications of abnormal scores. Height estimates from tibia length significantly overestimated standing height $(\mathrm{MB}=1.3 \mathrm{~cm}, \mathrm{LOA}=8.7)$ in our patient sample, but estimated height SDS showed a non-significant MB (-0.1SDS, LOA $=1.4 \mathrm{SDS})$ and a good agreement $(94 \cdot 3 \%$, kappa $=0.58)$ to abnormal SDS.

The obtained equations using ulna and tibia measurements in healthy children, adjusted for age and weight, could be alternatives to estimate height and diagnose abnormal SDS. However, results show height estimates from tibia length significantly overestimate measured height in our sample of paediatric patients. Considering the resulting SDS and abnormal SDS for height had a good agreement to those derived from standing height, these measurements might not be able to give an accurate estimate of standing height values but they could at least aid in identifying children with abnormal height to inform the nutritional assessment and management of these children when standing height is unfeasible. Further analysis and validation in a larger sample of patients with various conditions could help identify the best alternative to obtain an accurate estimate of height in different settings.

1. Pichler J, Hill SM, Shaw V, et al. (2014) Eur J Clin Nutr 1-6.

2. Bunting J \& Weaver LT (1997) J Hum Nutr Diet 10, 17-23.

3. Froehlich-Grobe K, Nary DE, Van Sciver A, et al. (2011) Am J Phys Med Rehabil 90, 658-66.

4. Cole TJ, Freeman JV \& Preece MA (1998) Stat Med 17, 407-29. 